\title{
Autophony of eyelid movement is not independent of eyeball movement
}

\author{
Mahmood F. Bhutta ${ }^{1}$
}

Received: 1 May 2018 / Accepted: 23 May 2018 / Published online: 5 June 2018

c) Springer-Verlag GmbH Germany, part of Springer Nature 2018

Bertholon et al. recently described characteristics of autophony of eyeball or eyelid movement in six patients with superior semicircular canal dehiscence (SSCD) syndrome [1]. They confirm my observation that autophony of eye movements is specific to this syndrome [2], but also report the novel finding of autophony of eyelid movement, which also appears to be specific to this syndrome.

However, the authors fail to consider that eyelid movement is not independent of eyeball movement. Several studies [3-5] show that the eyeballs invariably rotate downwards and inwards with each blink, with this movement starting just before the blink is initiated [4].

In the cohort of patients described by Bertholon et al., the majority described both autophony of eyeball and autophony of eyelid movement, but, admittedly, there were patients with only one of these symptoms. This could be interpreted as signifying independent aetiology, but the parsimonious explanation is that both these symptoms represent differing manifestations of autophony of eyeball movement. Perhaps those individuals who describe only autophony of eyelid movements do so because the downward and inward movement accompanying a blink is an otherwise unusual movement for the eyeball, and it is only when this specific eyeball movement occurs that these patients experience the symptom.

Bertholon et al. admit that autophony of eyeball and eyelid movement is difficult to explain. If, in fact, both these symptoms relate to eyeball movement, then my theory of direct transmission of extraocular muscle contraction to movement of the dura overlying the superior semicircular canal remains a valid and simple explanation [2].

Funding None.

\section{Compliance with ethical standards}

Conflict of interest Author MB declares that he has no conflict of interest.

Ethical approval This article does not contain any studies with human participants or animals performed by any of the authors.

\section{References}

1. Bertholon P, Reynard P, Lelonge Y, Peyron R, Vassal F, Karkas A (2018) Hearing eyeball and/or eyelid movements on the side of a unilateral superior semicircular canal dehiscence. Eur Arch Otorhinolaryngol 275(2):629-635

2. Bhutta MF (2015) Eye movement autophony in superior semicircular canal dehiscence syndrome may be caused by trans-dural transmission of extraocular muscle contraction. Int $\mathbf{J}$ Audiol 54(1):61-62

3. Bour LJ, Aramideh M, de Visser BW (2000) Neurophysiological aspects of eye and eyelid movements during blinking in humans. J Neurophysiol 83(1):166-176

4. Bergamin O, Bizzarri S, Straumann D (2002) Ocular torsion during voluntary blinks in humans. Investig Ophthalmol Vis Sci 43(11):3438-3443

5. Rambold H, Sprenger A, Helmchen C (2002) Effects of voluntary blinks on saccades, vergence eye movements, and saccadevergence interactions in humans. J Neurophysiol 88(3):1220-1233

This comment refers to the article available at https://doi. org/10.1007/s00405-017-4781-7.

Mahmood F. Bhutta

mahmood.bhutta@bsuh.nhs.uk

1 Department of ENT, Brighton \& Sussex University

Hospitals NHS Trust, Eastern Road, Brighton BN2 5BE, UK 